\title{
¿Liberales o proteccionistas? Estrategias económicas contrapuestas en la cadena automotriz argentina en las décadas del ‘'60 y ‘70
}

\section{¿Liberals or protectionists? Opposite economic strategies in Argentina automotive chain in the 60s and 70s}

\author{
Damián Bil \\ Centro de Estudios Urbanos y Regionales \\ Universidad de Buenos Aires \\ Consejo Nacional de Investigaciones Científicas y Técnicas \\ damibil@gmail.com \\ (Argentina)
}

Ianina Harari

Centro de Estudios e Investigaciones Laborales

Universidad de Buenos Aires

Consejo Nacional de Investigaciones Científicas y Técnicas

ianinaharari@yahoo.com.ar

(Argentina)

Gonzalo Sanz Cerbino

Centro de Estudios Urbanos y Regionales

Universidad de Buenos Aires

Consejo Nacional de Investigaciones Científicas y Técnicas

camilogx@yahoo.com

(Argentina) 


\title{
Resumen
}

Con el objetivo de comprender las estrategias de la clase capitalista en el país, proponemos aquí analizar la posición de los industriales del sector automotriz frente a la crisis orgánica de la sociedad argentina durante las décadas de 1960 y 1970. Es decir, estudiar las posturas asumidas por los empresarios y las corporaciones representativas de la actividad ante las diferentes coyunturas específicas de esos años, y en segundo término los conflictos dentro de la cadena asociados a esas circunstancias. Buscamos discutir la idea común en la historiografía, que sostiene que los capitales más concentrados defendieron un programa aperturista asociado a intereses extranjeros y de los sectores primarios, mostrando cómo los reclamos de las terminales automotrices de origen extranjero se inscriben en una estrategia que denominamos "liberaldesarrollista", pasada por alto en gran parte de los estudios sobre el particular. Utilizamos para alcanzar el objetivo información empresaria (Memorias y Balances contables, boletines), documentación de cámaras de industria, publicaciones periódicas especializadas, y aportes de otros investigadores.

Palabras Clave: Autopartistas, Terminales, Argentina, Estrategias, Estado

\begin{abstract}
In order to understand the strategies of the capitalist class in the country, we propose to analyze the position of automobile sector manufacturers to deal with the organic crisis of Argentine society during the 1960s and 1970s. In other words, we suggest studying the positions taken by businessmen and corporations in reponse to specific situations in those years. Then, we study the conflicts within the chain associated with those circumstances. We seek to discuss the common idea along historiography, which holds that the concentrated capital stood behind an open market program associated with foreign interests and primary sectors. We analyze how the demands of foreign automobile makers in Argentina are part of a "liberal developmentlist" strategy, overlooked in most of the studies on the subject. To achieve the objective, we used business information (Reports and balance sheets, newsletters), documents of industry chambers, journals, and contributions from other researchers.
\end{abstract}

Key Words: Auto parts, Terminals, Argentina, Strategies, State

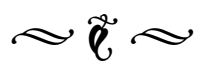

\section{Introducción}

En Argentina, el período 1955-1976 se caracterizó por la exacerbación de los enfrentamientos sociales. La sucesión de gobiernos civiles y militares, periódicas crisis políticas y de régimen, la apertura hacia 1969 de un proceso revolucionario, son manifestaciones de este fenómeno. ${ }^{1}$ Fue un momento en que las relaciones capitalistas fueron puestas en cuestión: la

1. SARTELLI, Eduardo (compilador) La crisis orgánica de la sociedad argentina, Editorial de la Facultad de Filosofía y Letras, Buenos Aires, 2011. 
Argentina se enfrentó a una crisis orgánica. ${ }^{2}$ El trasfondo era la crisis de acumulación, que se remontaba a la década del '50. La caída de los ingresos provenientes de la renta diferencial de la tierra hacía difícil seguir sosteniendo a importantes capas de la burguesía industrial que precisaban la protección del mercado interno. Tampoco había margen para sostener el nivel de vida de la clase obrera, cuyos símbolos eran las conquistas arrancadas al gobierno peronista. Los ingresos por exportaciones no alcanzaban a cubrir la demanda de divisas para importaciones, lo que derivaba en la aparición de "cuellos de botella" que repercutían negativamente a lo largo de toda la estructura económica, y cuya manifestación más recurrente eran la crisis de balanza de pagos y los brotes inflacionarios. La contracción de los ingresos imponía la necesidad de un ajuste: para sostener la acumulación de capital era necesario reducir los costos salariales, concentrar el capital eliminando a los sectores menos eficientes y reducir el gasto público. Sin embargo, resultaba difícil encontrar un personal político que pudiera avanzar en este sentido. Perón lo intentó con iniciativas como el Plan de Emergencia de 1952 y el Congreso de la Productividad de 1955, sin lograr un ajuste suficiente para relanzar la acumulación. Finalmente, terminó depuesto por un golpe militar. Sus sucesores tampoco lo lograron, lo que abrió un período de intensa disputa política que se expresó en la alternancia de gobiernos civiles y militares. A lo largo de todo este período la economía

2. La conjunción de una crisis hegemónica y una crisis de acumulación ponen sobre la mesa el agotamiento de la reproducción social, situación a la que denominamos crisis orgánica. Ver GRAMSCI, Antonio, Notas sobre Maquiavelo, sobre la política y sobre el Estado moderno, Nueva Visión, Buenos Aires, 2003, pp. 62 y ss.; SARTELLI, Eduardo, La sal de la tierra. Clase obrera y lucha de clases en el agro pampeano (1870-1952), Ediciones ryr, Buenos Aires, 2017, en prensa. tuvo un desempeño errático: fases de expansión eran seguidas por la contracción del producto. Los "planes de estabilización", que conjugaban la devaluación de la moneda con el congelamiento de los salarios reales, constituían la forma de descomprimir los cuellos de botella, inaugurando las fases recesivas. En esos momentos el salario real se contraía, pero esa política no lograba mantenerse en el tiempo. La conflictividad social que emergía como resultado del intento de imponer un "ajuste", permitía la recuperación de los salarios. Sin embargo, los ataques permanentes a las conquistas de la clase obrera fueron horadando las bases de la dominación social. La crisis de acumulación devenía así en crisis hegemónica.

La necesidad de avanzar con un ajuste exacerbaba los enfrentamientos entre clase obrera y burguesía, pero también dentro de la propia clase dominante. Las interpretaciones más difundidas sobre la pugna interburguesa postulan la confrontación entre dos polos: de un lado, la gran burguesía agraria e industrial, aliada del imperialismo (la oligarquía, los monopolios o las trasnacionales, son algunas de las denominaciones que se utilizan); del otro, a la burguesía pequeña y mediana, que expresaría intereses nacionales (y, para algunos, populares). En términos políticos, la división se expresaría entre peronistas y anti-peronistas; $y$ en términos programáticos entre liberalismo y nacionalismo/mercado-internismo. ${ }^{3}$ Estas visiones sobre

3. Esta lectura de la conflictividad interburguesa entre la década de 1960 y 1970 parte de la hipótesis que postula que tanto la burguesía agropecuaria como el gran capital industrial en la Argentina no tendrían interés en el desarrollo nacional, ya que se beneficiarían de una estructura económica que perpetuaría el atraso. Ver por ejemplo PEÑA, Milcíades, Industrialización $y$ clases sociales en la Argentina, Hyspamérica, Buenos Aires, 1986; SÁBATO, Jorge, La clase dominante en la Argentina moderna, Imago Mundi, Buenos Aires, 
el conflicto interburgués presentan múltiples problemas. El principal es que pasan por alto que, en la coyuntura analizada, no son dos los programas de la burguesía, sino tres. Lo que se esconde bajo el mote de "liberales" son fracciones con intereses contrapuestos, que plantean estrategias diferentes para clausurar la crisis. No se trata de una omisión menor, ya que el programa que se desdibuja es el de la fracción de la burguesía que logra imponerse en 1976, cerrando la crisis hegemónica y relanzando la acumulación. Aquí intentaremos ver cómo se expresaron estas diferencias mediante un estudio de caso. Comenzaremos con un análisis de los programas que esgrimieron las diferentes capas y fracciones de la clase dominante frente a la crisis abierta en 1955, postulando la existencia de tres alternativas: el programa liberal agropecuario, el programa de liberación nacional y el programa liberal desarrollista. A continuación reconstruiremos los alineamientos y los conflictos de los distintos eslabones de la cadena automotriz durante las décadas de 1960 y 1970 . Como veremos, las demandas contrapuestas de las terminales automotrices y

1991 y SCHVARZER, Jorge, Empresarios del pasado. La Unión Industrial Argentina, CISEA-Imago Mundi, Buenos Aires, 1991. Durante la coyuntura analizada, ello se manifestaría en la oposición de estas capas de la clase dominante a las políticas de industrialización asociadas al peronismo, en su apoyo a los gobiernos originados en golpes de estado y en su adscripción a las ideas del "liberalismo económico". Ver BASUALDO, Eduardo, Sistema político y modelo de acumulación en la Argentina, Universidad Nacional de Quilmes, Bernal, 2001; BRENNAN, James y ROUGIER, Marcelo, Perón y la burguesía nacional, Lenguaje Claro, Buenos Aires, 2013; HEREDIA, Mariana, "El proceso como bisagra. Emergencia y consolidación del liberalismo tecnocrático: FIEL, FM y CEMA", en PUCCIARELLI, Alfredo (coordinador) Empresarios, tecnócratas y militares, Siglo XXI, Buenos Aires, 2004, pp. 313-382; SIDICARO, Ricardo, Los tres peronismos, Siglo XXI, Buenos Aires, 2002; VERBITSKY, Horacio y BOHOSLAVSKY, Juan Pablo, Cuentas pendientes, Siglo XXI, Buenos Aires, 2014. la industria autopartista no pueden entenderse a la luz de la dicotomía entre "liberales" y "proteccionistas". Nuestra hipótesis es que las debilidades del capital industrial en la Argentina, independientemente de su escala, impiden que cualquiera de sus capas (grandes o chicas) pueda adscribir a las posiciones identificadas con el "liberalismo". Todos necesitan, en mayor o menor medida, de ciertos niveles de protección frente a la competencia extranjera. Así, mientras el eslabón más débil de la cadena, los autopartistas, se alineaba con las posiciones que denunciando la dependencia postulaban la generalización de los mecanismos proteccionistas, las terminales proponían, como la burguesía "liberal-desarrollista", reducir la protección para los capitales de menor tamaño al tiempo que exigían sostener los mecanismos que resguardaban su negocio de la competencia extranjera.

\section{Los programas en pugna}

La primera de las tres propuestas económico-sociales de la clase dominante frente a la crisis orgánica, la de la burguesía agropecuaria pampeana, puede reconstruirse a partir de los posicionamientos de sus corporaciones. ${ }^{4}$ En la etapa, éstas tuvieron coincidencias que sintetizaron en una serie de documentos. El más importante de ellos es "El agro y el de-

4. Estas corporaciones son Federación Agraria Argentina (FAA), representante de las capas más débiles de la burguesía agropecuaria, arrendataria y propietaria; Confederación Intercooperativa Agropecuaria (CONINAGRO), representante del cooperativismo agropecuario; Sociedad Rural Argentina (SRA) y Confederaciones Rurales Argentinas (CRA), representantes de la burguesía terrateniente mediana y grande. 
sarrollo nacional" ${ }^{5}$, resultado de un proceso de confluencia entre las cuatro corporaciones rurales pampeanas. Hacia fines de 1970, tras dos asambleas multitudinarias, se acordó la conformación de un frente denominado $\mathrm{Co}^{-}$ misión de Enlace (en adelante, $\mathrm{CE}$ ), que integraban la Federación Agraria Argentina (en adelante, FAA), la Sociedad Rural Argentina (en adelante, SRA), Confederaciones Rurales Argentinas (en adelante, CRA) y la Confederación Intercooperativa Agropecuaria (en adelante, CONINAGRO). En esas asambleas se votó el documento mencionado, un verdadero programa común que sintetizó la propuesta económica, política y social de la burguesía agropecuaria pampeana.

Uno de los ejes del documento es el juicio negativo sobre la política económica de los 30 años previos, que consideraban guiada por una misma premisa: la transferencia de ingresos del agro hacia otros sectores. Desde Perón a Onganía, todos habrían aplicado políticas nocivas para el agro, "estrangulando" sus ingresos. El resultado sería el estancamiento sectorial, que inexorablemente llevaba al estancamiento nacional. Cuestionaban aquellas medidas para captar y distribuir renta: impuestos, "tipos de cambio desfavorables", restricción de importaciones que obligaba a pagar los altos precios de la industria nacional, o la centralización del comercio exterior. ${ }^{6}$ Asimismo, criticaban el destino que se daba a esos recursos. En primer lugar, objetaban la existencia de un Estado so-

5. El escrito sintetiza una serie de posiciones que pueden rastrearse en otros documentos de estas corporaciones: comunicados publicados en periódicos nacionales, publicaciones corporativas como las Memorias y Balances, o el semanario La Tierra de FAA.

6. CRA, SRA, FAA, CCEA y CONINAGRO: "El agro y el desarrollo nacional. Conclusiones”, Buenos Aires, 17 de noviembre de 1970, pp. 9-18. bredimensionado e ineficiente. Denunciaban que, "en lugar de reducir el gasto público, se lo ha aumentado con nuevos organismos... que, en última instancia, siempre pagan los sectores productivos más eficientes de la población". ${ }^{7}$ Cuestionaban los gastos sociales y las políticas que, mediante control de precios sobre los productos agropecuarios, transferían ingresos hacia los asalariados "subsidiando el consumo". Por último, discutían las transferencias destinadas a sostener un esquema proteccionista y de subsidios a la burguesía urbana, que habría dado lugar a una errónea política de "sustitución de importaciones" que permitiría la subsistencia de "industrias con niveles de eficiencia relativamente bajos". ${ }^{8}$

Sostenían que la única forma de superar la crisis era apuntalar la acumulación de los sectores competitivos (el agro) y eliminar las transferencias a los ineficientes. El corazón de este programa, que denominamos "liberalismo agropecuario" era la defensa de una riqueza social que la burguesía rural consideraba propia (la renta) y la oposición a los mecanismos estatales para apropiarse de ella y distribuirla hacia otros actores. En su concepción, la sustracción de parte de los ingresos del agro para subsidiar la industria o el consumo, liquidaba al único sector capaz de impulsar el desarrollo nacional, condenándolo al estancamiento y con él, a todo el país. Su planteo apuntaba a evitar este tipo de transferencias, por eso exigían una racionalización del Estado y el saneamiento de la industria eliminando a los menos eficientes. Esa era la forma que adquiriría el "restablecimiento de la rentabilidad" del agro: concentración y centralización industrial, cierre de toda industria incapaz de competir sin protección,

7. Ídem, p. 5.

8. Ibídem. 
achicamiento del Estado, desocupación y bajos salarios. Es el programa que tradicionalmente se identificó con el "liberalismo", al que, como veremos, no podía adscribir ninguna capa de la industria.

En oposición al liberalismo agropecuario se ubicó la propuesta de la burguesía industrial más débil, orientada al mercado interno, ligada al peronismo y organizada en la Confederación General Económica (en adelante, CGE). El documento que mejor la sintetiza es el trabajo escrito por el ensayista Daniel Larriqueta y por Julio Broner, empresario autopartista que presidió la CGE entre 1973 y $1976 .{ }^{9} \mathrm{E} 1$ dilema planteado por estos autores se resumía en la contradicción "liberación o dependencia", por lo que decidimos denominar la propuesta como "programa de liberación nacional". El país, sostenían, debía afirmar su autonomía a partir del desarrollo industrial autónomo, por contraposición a las vías que acentuarían la "dependencia". Sostenían que "si utilizamos modelos y políticas económicas que busquen la prosperidad material a cualquier precio, $\mathrm{CO}^{-}$ rremos el riesgo de convertir al país en una colonia rica". Sus propuestas, en cambio, "se engarzan en esta concepción ideológica del desarrollo material como parte del fortalecimiento de la Nación". ${ }^{10}$ Por ello, propugnaban el desa-

9. BRONER, Julio y LARRIQUETA, Daniel, La revolución industrial argentina, Sudamericana, Buenos Aires, 1969. Este texto sintetiza una serie de posiciones que fueron vertidas en otros documentos, como por ejemplo aquellos firmados por la CGT y la CGE, o los que surgieron de las reuniones entre la CGE y los representantes de partidos políticos. Ver AA.VV., "Coincidencias programáticas del plenario de organizaciones sociales y partidos políticos", en MINISTERIO DE ECONOMÍA, Politica económica para la reconstrucción y la liberación nacional, Legislación Económica, Buenos Aires, 1975, pp. 213-222.

10. BRONER, Julio y LARRIQUETA, Daniel, $L a$ 6 rrollo de una industria sustitutiva apuntalada por políticas económicas proteccionistas. De esa forma, se podría avanzar por el camino de independencia política y económica.

La propuesta apuntaba a brindar una protección amplia que diera cobijo a todas las capas de la burguesía manufacturera, especialmente a las pymes y a las empresas de capital nacional. Recurriendo a todo el bagaje conceptual del nacionalismo y a las supuestas desventajas de los "monopolios", estas capas de la burguesía elaboraron una ideología a su medida, en donde la defensa de los "intereses nacionales" aparecía como sinónimo de subsidiar a las capas más débiles de la burguesía industrial argentina.

Sin embargo, en la Argentina de los '70 había más de una "estrategia de desarrollo industrial" en discusión: la estrategia de la burguesía agropecuaria y la de los grandes industriales, que a diferencia de lo propuesto por Broner y Larriqueta, pretendían orientar el desarrollo en función de la demanda externa. El programa de liberación nacional, según Broner y Larriqueta, se diferenciaba de ellos al centrar su propuesta en el abastecimiento del mercado interno, en lo que denominaron el crecimiento "hacia adentro". Planteaban que en la Argentina existía una demanda potencial no desarrollada, a la que se debían incentivar promoviendo la radicación de polos industriales y un mayor consumo en el interior del país. Esta era la única forma en que podía resultar compatible la idea de un mayor desarrollo industrial con una nula preocupación por los costos o la eficiencia: la industria que defendían solo podía expandirse en los estrechos límites del mercado interno. Por eso, Broner y Larriqueta cuestionaban

revolución industrial..., Op. Cit., p. 156. 
las estrategias de expansión industrial que proponían como base las exportaciones, que consideraban "inviables". La industria argentina no podría exportar en una magnitud suficiente para impulsar el desarrollo industrial, sostenían, ya que no había una situación de demanda insatisfecha en el mercado mundial. No se consideraba, por supuesto, que la industria argentina pudiera alcanzar una inserción internacional sobre la base de mejores costos. Por el contrario, objetaban toda la literatura que ponía en cuestión la competitividad y los altos costos de la industria argentina. Para sostener el proceso de industrialización sustitutiva, afirmaban, "nuestros costos tendrán que seguir siendo durante un tiempo indefinidamente mayores que los de otros países especializados". ${ }^{11}$ Una estrategia orientada al mercado externo implicaría dejar librado a su suerte a buena parte del entramado industrial, incapaz de competir, al tiempo que acentuaría la "extranjerización" y la "dependencia”. Así como los representantes del agro, "partidarios de una estrategia llamada de economía abierta”, presuponen que "la Argentina debe disminuir o incluso retrotraer el proceso de sustitución”, lo mismo se encontraría implícito en las propuestas que postulaban un desarrollo industrial orientado hacia la exportación. Quienes suponen que el país "debe optar por alguna forma de especialización industrial" limitarían las posibilidades de crecimiento y lo condenarían a nuevas formas de "colonialismo". Este tipo de propuestas, a su vez, incentivaría el arribo de capitales trasnacionales, otra forma de acentuar la "dependencia". ${ }^{12}$

Con estos argumentos, justificaban su propuesta político-económica: multiplicar la pro-

11. Ídem, p. 164.

12. Ídem, pp. 25-26, 47-48 y 105-158. tección y los subsidios para sostener a todas las capas de la burguesía industrial, sin importar su eficiencia, su escala o su capacidad de inserción internacional. Sin embargo, este programa se enfrentaba a un límite impuesto por la dinámica económica: ¿cómo sostener esa política si las divisas de las exportaciones agropecuarias ya no alcanzaban? A su criterio, los recursos para los subsidios debían surgir del agro, que podía producir más. Por razones estructurales, el campo se encontraría dominado por relaciones no capitalistas y los "terratenientes" no realizarían las inversiones necesarias para aumentar la productividad. La solución radicaba en la aplicación de herramientas que forzaran a los terratenientes a invertir o una reforma que permitiera el arribo al campo de "productores eficientes". De esta manera se podría superar el "retraso agropecuario", y arribarían las divisas necesarias para sostener la protección generalizada. ${ }^{13}$ Cabe aclarar que esta caracterización del agro argentino, de la que dependía la propuesta económica de estos sectores, fue rebatida por el desarrollo del sector, que multiplicó la producción y los saldos exportables desde los ‘60, con la incorporación de modernos avances tecnológicos.

Para finalizar, ubicándose en algún punto intermedio de la disputa entre "liberales" y "populistas", encontramos un tercer programa: el de la burguesía industrial de mayor tamaño. Esta fracción, que dominó la Unión Industrial (en adelante, UIA) Argentina entre 1955 y 1972, y que supo formar alianza con la burguesía agropecuaria en distintos momentos, se vio obligada a constituir una organización propia en 1967, desde la cual desplegar sus propuestas. Así nació el Consejo Empresario Argentino (en adelante, CEA), a través del

13. Ídem., pp. 28-40. 
cual buscaron incidir sobre el personal político con una propuesta propia, diferente al de los pequeños industriales que también integraban la UIA y al de la burguesía agropecuaria, con la que compartían los frentes anti-populistas. El CEA fue una organización que reunió a 30 de los capitales más concentrados, nacionales y extranjeros. A diferencia de otras corporaciones, no se organizaba por ramas: lo integraban representantes de capitales agropecuarios, comerciales y financieros, con predominancia de la burguesía industrial de mayor tamaño. ${ }^{14}$ Entre 1967 y 1976, nucleó a las dos siderúrgicas privadas más grandes del país (Acindar y Techint) y una metalúrgica destacada (Astarsa); la más importante productora de papel (Celulosa Argentina); las químicas y petroquímicas de mayor tamaño (Ducilo, $\mathrm{Du}$ perial, PASA, Ipako, Electroclor, Monsanto y

14. La composición del CEA se pueden consultar en BAUDINO, Verónica, La estrategia de la Unión Industrial Argentina 1966-1976, Tesis Doctoral, Universidad de Buenos Aires, 2012, p. 179 y en MUCHNIK, Daniel, Argentina modelo, Manantial, Buenos Aires, 1998, p. 116. La información sobre las empresas o grupos que estos dirigentes empresarios representaban fue tomada de distintas fuentes primarias y secundarias. Para un análisis detallado, ver: SANZ CERBINO, Gonzalo, "La lógica del enemigo. Los programas de la burguesía argentina y sus límites, 1955-1976", en Razón y Revolución, Buenos Aires, 2016, № 29, pp. 151-198. Para un análisis de las características de las empresas y ramas ligadas al CEA, ver AZPIAZU, Daniel, La industria celulósica-papelera, su evolución histórica y perspectivas futuras, Instituto Nacional de Planificación Económica Argentina, Buenos Aires, 1977; GORENSTEIN, Silvia, "El Complejo Petroquímico Bahía Blanca: algunas reflexiones sobre sus implicaciones espaciales", en Desarrollo Económico, Buenos Aires, 1993, V. 32, No 128, pp. 575-601; CASTRO, Claudio, "De proveedor del Estado a empresa multinacional: Siderca entre 1960 y 1996", en ROUGIER, Marcelo (compilador) Estudios sobre la industria argentina, Lenguaje Claro, Buenos Aires, 2013; CASTELLANI, Ana, Estado, empresas y empresarios. La construcción de ámbitos privilegiados de acumulación entre 1966 y 1989, Prometeo, Buenos Aires, 2009.
Compañía Química de Bunge y Born); importantes petroleras (Astra, Cities Services, y la Compañía General de Combustibles); constructoras como Gesiemes del Grupo Soldati, Techint Ingeniería, Lanusse y Polledo S.A.; algunas agroindustrias (Molinos Río de la Plata, Massalin, la yerbatera Las Marías, Noel S.A., Ingenio E1 Tabacal y FASA); las textiles que dominaban el mercado local (Alpargatas, Grafa y Ducilo); la cementera Loma Negra, neumáticos Pirelli y las automotrices más relevantes (Fiat, Ford e IKA-Renault). Además de tener en común su carácter predominantemente industrial, estos capitales se destacaban por su escala, que les permitía dominar el mercado interno e incluso exportar eventualmente. Esto no implicaba que pudieran prescindir de la protección. Por el contrario, estas empresas se encontraban entre las más favorecidas por el esquema proteccionista. Varias se beneficiaron de la protección a las industrias sustitutivas de insumos básicos, automotrices y textiles, contando con aranceles que restringieron el ingreso de competidores, financiamiento preferencial y desgravaciones impositivas en los marcos de los regímenes de promoción industrial. Cabe agregar la integración de varios de estos capitales al Estado, como proveedores o adquiriendo insumos a precios preferenciales de empresas como YPF o Gas del Estado.

Esta dependencia de la protección explicaba por qué, a pesar de haber compartido frentes con la burguesía rural, no podían comulgar con su programa. Sus posiciones en temas como la protección para la industria o la reducción de gastos estatales los alejaban del programa del agro. ${ }^{15} \mathrm{~A}$ diferencia de lo levantado por los

15. En el caso del CEA, no existen documentos que sinteticen sus posiciones. Por esa razón, hemos recurrido a escritos y testimonios de sus dirigentes, publicados en revistas especializadas como Mercado o Panorama de la 
capitales débiles, la gran burguesía industrial parecía consciente de la necesidad de "ajustar" variables para restablecer el equilibrio. Por eso, coincidieron con la burguesía rural en la necesidad de "disciplinar" a los trabajadores, aumentar la productividad y reducir los salarios. ${ }^{16}$ Diferían en este punto de los partidarios del programa de "liberación nacional", que en ciertas coyunturas se habían mostrado permeables a conceder mejoras salariales para dinamizar el mercado interno. Los integrantes del CEA también expresaron la necesidad de "modernizar" el entramado industrial, para ganar competitividad. ${ }^{17}$ Otra coincidencia con la burguesía agropecuaria era la necesidad de reducir gastos estatales. Por ejemplo, hacia 1968, Taboada (FASA) y Aguilar (Ducilo) proponían aumentar la eficiencia estatal y aliviar la presión tributaria que "descapitalizaba" a las empresas. ${ }^{18}$ En septiembre de 1976, Edmundo Paul, presidente de Celulosa, señalaba que el principal desafío para los militares era la rebaja del gasto. Conectaba los "excesivos" gastos del Estado con una presión tributaria que "atrofiaba" al capital privado. ${ }^{19}$

Sin embargo, no debe deducirse de estas intervenciones la propuesta de un "Estado mínimo", más cercana al programa agropecuario. Ni siquiera Martínez de Hoz, presidente del CEA en 1975 y ministro de Economía de la dictadura, a quién livianamente se suele iden-

\section{Economia Argentina.}

16. Como sostenían Dietl (Celulosa), Rocca (Techint), César Polledo (Polledo S.A.) y Braun Cantilo (Astarsa) a fines de 1975 (Mercado, Buenos Aires, 28/8/1975).

17. Mercado, Buenos Aires, 5/2/1970, 10/9/1970 y 6/5/1976.

18. Panorama de la Economía Argentina, Buenos Aires, 1968, No 39.

19. Mercado, Buenos Aires, 2/9/1976. tificar con el liberalismo extremo, ${ }^{20}$ sostenía este tipo de posiciones. En junio de aquel año, señalaba que al Estado le correspondía "el control de la economía" y que debía "impulsar" el desarrollo mediante mecanismos de "estímulo y desaliento". ${ }^{21}$ Rocca (Techint), aunque defendía un mercado en el que no sea "el Estado quien determine todo lo que se tiene que hacer", no dejaba de marcar un límite que lo distanciaba del liberalismo: "aclaramos: nada de laissez faire. El Estado no podrá estar ausente. Después de la crisis del'30 el Estado orientador y regulador de la economía pasó a ser una realidad en el mundo."22

La posición de estos capitales en la estructura económica puede explicar estas afirmaciones. Como representantes de intereses industriales que dependían de la protección, no podían defender un "Estado mínimo". Pero al tratarse de las capas más concentradas de la burguesía industrial, podían proponer como solución un ajuste sobre una porción del gasto, el que se utilizaba para subsidiar a las capas más débiles de la industria y el nivel de vida de los asalariados. La misma lógica se replicaba con el proteccionismo. Los aranceles que resguardaban la producción de ciertos bienes "estratégicos" fueron defendidos por integrantes del CEA, al igual que la "promoción industrial", que contemplaba beneficios y subsidios para inversiones en ciertas ramas y regiones. ${ }^{23}$ Sin embargo, la propuesta del CEA no coincidía con la de la burguesía industrial más débil. Protección y estímulos no debían generalizarse. Debían con-

20. Ver por ejemplo BASUALDO, Eduardo, Sistema politico..., Op. Cit.

21. Mercado, Buenos Aires, 5/5/1975.

22. Mercado, Buenos Aires, 6/5/76.

23. Mercado, Buenos Aires, 23/12/1969, 6/8/1970, 28/11/1974, 4/12/1975 y 2/9/1976. 
centrarse en los "más eficientes", que pudieran alcanzar en cierto plazo la competitividad que les permitiera independizarse de la tutela estatal. La contracara era la condena para los capitales más débiles, a los que debía retirarse la protección. Así se avanzaría en el saneamiento de la economía, sin afectar a los capitales de mayor tamaño nucleados en CEA. ${ }^{24} \mathrm{La}$ gran burguesía industrial, nacional y trasnacional, estaba lejos de patrocinar las posiciones tradicionalmente asociadas al "liberalismo" que defendía la burguesía agropecuaria. Su posición en el debate sobre la promoción, cuando los recursos escaseaban, estaba entre el liberalismo y el proteccionismo nacionalista. Con los primeros compartía la necesidad de realizar un ajuste, que redujera los costos salariales, gastos fiscales y la protección hacia buena parte de los capitales más débiles, abriendo paso a un proceso de concentración. Con los segundos compartía la necesidad de mantener cierta protección y subsidios, para la supervivencia de los grandes capitales que representaban. Por eso, denominamos esta propuesta "programa liberal-desarrollista”.

En síntesis, podemos decir que la clásica dicotomía utilizada para explicar el conflicto interburgués en los ' 60 y ' 70 , entre nacionalistas proteccionistas y liberales aperturistas, debería ser matizada. Como hemos visto, lo que históricamente se ha conocido como "liberalismo" en la Argentina esconde dos programas. Uno ligado al agro, que proponía un ajuste feroz, reduciendo al mínimo las transferencias de renta, $y$ propugnando en consecuencia el recorte de los gastos públicos, el disciplinamiento de los trabajadores y el fin del proteccionismo industrial; el otro ligado a las capas más concen-

24. Mercado, Buenos Aires, 23/12/1969, 5/3/1970, 19/12/1970 y 4/12/1975. tradas de la industria, que coincidía en la necesidad del ajuste con la burguesía agropecuaria, pero imponiendo un límite: el mantenimiento de un proteccionismo selectivo que resguardara sus privilegios. Ambos se oponían a las políticas impulsadas por la burguesía industrial más débil, ligada a la CGE y el peronismo, que impulsaba un proteccionismo generalizado que garantizara la supervivencia de todas las capas de la industria. A continuación, analizaremos las disputas al interior de la cadena automotriz a la luz de estos planteos sobre la conflictividad interburguesa en la etapa.

\section{La fractura entre los autopartistas y la industria terminal}

La rama automotriz está compuesta por dos sectores fundamentales: autopartistas y terminales. Cada uno abrazó propuestas distintas en el período, lo que los condujo a un enfrentamiento abierto en los '70: mientras que los primeros constituyeron una de las bases de los que abogaban por la "liberación nacional" y el proteccionismo generalizado, las terminales se alinearon con los defensores del liberalismo-desarrollista, reclamando protección para sí y apertura para el mercado de autopartes. En este escenario también se desarrollaban disputas regionales en torno a las políticas públicas y la radicación de plantas que continuaron hasta los 80 , sobre todo a nivel de las terminales. ${ }^{25}$

25. Para profundizar sobre los problemas y estrategia específica de cierto sector del autopartismo en términos regionales, ligado a la industria metalúrgica, remitimos al lector a los trabajos de Simonassi. Ver SIMONASSI, Silvia, Historias del Metal. Industria e industriales metalúrgicos en Rosario, 1973-1983, Tesis de Maestría, Facultad Latinoamericana de Ciencias Sociales (FLACSO), 2004; Simonassi, Silvia, "Entre la adhesión activa y el desencanto. Acerca de los industriales 
Aquí nos concentraremos en los conflictos entre terminales y autopartistas, dejando para futuros análisis las disputas regionales que merecen a nuestro entender un abordaje específico. En particular, nos detendremos en los debates sobre el régimen automotriz, centrándonos en la disputa por los aranceles y las cuotas de importación. Si bien este no es el único frente de conflicto, tiene una importancia central porque en su sanción se expresan los distintos intereses en torno a la política para la actividad. Por eso, consideramos fundamental profundizar en este particular.

La fabricación integral de automotores surgió en la segunda mitad de los '50 en la Argentina, al amparo del Estado. Las dificultades económicas desde los '30 llevaron a un envejecimiento del parque automotor que se agravó luego de la guerra. ${ }^{26}$ Por eso, se estableció un sistema de protección con incentivos para la radicación de capitales. El Estado comenzó a fabricar con IAME, financiando proveedores y generando condiciones para los privados. En marzo de 1959, se sancionó el Régimen de Promoción de la Industria Automotriz, que elevaba aranceles para autos terminados o prohibía su importación. Estableció un nivel de integración nacional de autopartes, aunque permitía importar hasta dos tercios del va-

metalúrgicos del Gran Rosario y el Proceso", en Avances del CESOR, Rosario, 1998, № 1, pp. 95-107. Sobre el caso de Córdoba, remitimos a: BAUDINO, Verónica, “La Fundación Mediterránea y la burguesía nacional”, en Razón y Revolución, Buenos Aires, 2004, o 12, pp. 161171; RAMÍREZ, Hernán, “La fundación Mediterránea y de cómo construir poder. La irrupción del interior en el diseño de la política económica argentina”, en História Econômica E̊ História de Empresas, No 2, V. 4, 2001, pp. 131-161.

26. SOURROUILLE, Juan, Transnacionales en América Latina. El complejo automotor en Argentina, México, Nueva Imagen, 1980. lor del vehículo con un arancel del $62 \% .{ }^{27} \mathrm{La}$ prohibición de traer autos y la posibilidad de importar piezas con recargo moderado generó una andanada de pedidos de instalación, y se radicaron 23 terminales. El fenómeno fue general: las multinacionales debieron instalar plantas para atender mercados como el local, el brasileño o mexicano. En la rama existía otra razón para la radicación: el costo del transporte. Dado un tamaño y distancia del centro de consumo, resultaba conveniente instalar una planta de ensamblado. Así, se instalaron grandes multinacionales que convivían con pequeños grupos como IASF, Marimón o Siam. ${ }^{28} \mathrm{El}$ régimen permitió que pequeños capitales se establecieran como ensambladores de piezas importadas para producir con licencias extranjeras. Por la protección y la demanda insatisfecha, se expandieron.

Para 1964-65, se estipuló que el contenido de autopartes importadas no debía pasar el 10\% y también montos mínimos de inversión para considerar a las empresas dentro del régimen automotriz. Las que aprovechaban la importación barata y solo ensamblaban, y otras que no podían afrontar inversiones mínimas, cerraron. Para 1970, solo quedaba la estatal DINFIA y nueve transnacionales. La profundización del "compre nacional" mediante la reducción del cupo de importaciones de piezas redundó en la concentración a favor de las

27. NOFAL, María, Absentee Entrepreneurship and the Dynamics of the Motor Vebicle Industry in Argentina, Praeger, New York, 1989; FITZSIMONS, Alejandro, "Notas sobre la valorización de los capitales extranjeros automotrices en Argentina (1959-63)", ponencia presentada en VII Jornadas de Economía Crítica, Sociedad de Economía Crítica, La Plata, 2014.

28. VICENTIN, Enzo, "La empresa automotriz IASFSA en Santa Fe. Características de una experiencia en los márgenes (1959-1969)", en Avances del CESOR, Rosario, 2013, No 10, pp. 9-33. 
extranjeras y la quiebra de los "nacionales", que eran los más débiles en la competencia. Se aceleró el proceso de centralización, renovación técnica y aumento de producción. Pero la rama mantuvo sus dificultades, en particular sus costos: en 1965, un Rambler o un camión costaba 2,5 veces más que en EE.UU; $36 \%$ más que en Brasil y $54 \%$ más en relación a México. El reducido mercado no permitía superar esas dificultades. En 1970 el mercado argentino era casi dos veces menor al brasileño, seis veces menor al francés y treinta y siete veces menor al norteamericano. Mientras en EE.UU. se producían 11.112.000 vehículos, en Argentina solo $196.800 .{ }^{29}$ En autopartes, a fines de los ' 60 , Wobron producía 320 mil conjuntos de embragues. La Ferodo producía en Francia 4 millones. Valeo, en Italia, 1,3 millones. ${ }^{30}$

La producción se sostuvo por la compensación a partir de la intervención estatal, con protección arancelaria, superior a la del resto de la economía, o con la prohibición de importar vehículos. Se reducía la competencia externa, y la rama podía reproducirse con costos y precios mayores. No obstante, encontraba límites. Por un lado, la expansión previa generó una capacidad ociosa que el mercado interno no podía absorber. Eso implicó una agudización de los problemas financieros y de operación. La posibilidad de subsidiar la actividad con créditos internos o con el fomento a la exportación seguía el ritmo de la economía argentina, sumida en ciclos inestables (stop and go) con años de indicadores positivos seguidos de otros muy malos, como la bonanza de 1974 seguida de la

29. BARANSON, Jack, La industria automotriz en los países en desarrollo, Tecnos, Madrid, 1971.

30. Estudio de caso relativo a la fabricación de embragues y discos de embrague en Argentina y Chile, CEPAL, Santiago, 1970.

12 debacle de 1975. Como observaba Sourrouille, a comienzos de los '70 esto se tradujo en una crisis de rentabilidad, que empalmó con la crisis mundial del sector entre 1978-82, provocando la reestructuración en la rama.

\section{Dos programas en la industria automotriz}

Los que integraban el complejo tendieron a alinearse en veredas opuestas en las disputas de los '60 y '70: mientras que los autopartistas adhirieron al programa de liberación nacional, las propuestas de las terminales podrían englobarse en la alternativa liberal-desarrollista. Esto obedecía, en primer lugar, a los diferentes niveles de concentración de los capitales. Además, entre las autopartistas predominaban los capitales nacionales. Aquí existía un polo de empresas de cierta magnitud que producían con licencias internacionales, y una miríada de pequeños talleres que mecanizaban piezas, fundamentalmente para reposición. ${ }^{31} \mathrm{Si}$ bien ambos eslabones podían tener intereses compartidos, había problemas que los enfrentaban. Esas diferencias afloraron a comienzos de los '70, cuando en un contexto de crisis se batieron en combate abierto.

Ambos sectores se organizaron corporativamente para defender sus reivindicaciones. Las terminales se nuclearon en la Asociación de Fábricas de Automotores (en adelante, ADEFA) mientras que los autopartistas lo hicieron en dos cámaras: la Cámara Argentina de la Industria de Autocomponentes (en adelante, CAIA) asociada a UIA; y la Cámara Industrial de Fabricantes de Autopartes de la República

31. NOFAL, María, Absentee Entrepreneurship..., Op. Cit., p. 38. 
Argentina (en adelante, CIFARA) adherida a CGE y cuyo hombre fuerte era Broner, dueño de Wobron. Cabe aclarar que entre los autopartistas no solo existían empresas nacionales, sino también filiales de grandes multinacionales (Hoesch, SKF, Bosch, Pirelli, entre otras), mayormente asociados a la CAIA. Sin embargo, en los eventos aquí analizados ambas corporaciones sostuvieron las mismas posiciones.

Las cámaras autopartistas levantaron reivindicaciones diversas. La consigna fundamental de CIFARA era la protección del mercado interno, con un "amplio criterio patriótico", resguardando a las autopartistas con los principios del "Compre Argentino". CIFARA sostenía los pilares que estructuraban la CGE: defensa del mercado interno, de las fuentes laborales y del producto nacional en el exterior, economía de divisas vía sustitución y fomento de exportaciones, y una política de conciliación para armonizar la relación capital-trabajo. ${ }^{32}$ Desde el reclamo de protección frente a productores más competitivos, estructuraban reivindicaciones puntuales. En sus reclamos al Estado, se focalizaban en la dificultad de importar materias primas, equipamiento e insumos, afectando la calidad. Asimismo, reclamaban por la falta de créditos. También denunciaban las facilidades con las que supuestamente contaba la importación de terminados, como las disposiciones que reducían aranceles al sur del paralelo $42^{\circ} .{ }^{33}$ CIFARA presionó para prohibir la importación de productos que la industria nacional pudiera aportar en calidad y cantidad suficiente, y exigió restricciones a la radicación de firmas extranjeras aun cuando elaboraran

32. Industria Automotriz, Buenos Aires, Año 2, № 10-12, julio-diciembre de 1958.

33. Industria Automotriz, Buneos Aires, Año 1, No 1, enero-febrero de 1957. conjuntos que aquí no se hicieran. La tramitación de licencias con líderes mundiales perseguía este doble objetivo: incrementar la capacidad a partir de la asistencia técnica y de insumos; y evitar que la multinacional viniera a disputar el mercado doméstico.

Otro eje era la normalización y estandarización de piezas. ${ }^{34}$ Hacia fines de los ‘50, CIFARA consiguió el apoyo del Instituto Argentino de Normalización y Certificación (en adelante, IRAM) para obtener normas. Por su parte, la estandarización buscaba la intercambiabilidad para eliminar piezas superfluas, bajando costos y aumentando la productividad. En este sentido se planteaba una disputa con las terminales, que atribuían a la baja calidad y alto precio de las autopartes nacionales el elevado costo de los vehículos, y en base a ello recalcaban la necesidad de relajar los permisos de importación de piezas y conjuntos. Los autopartistas, sin negar el problema de precios y calidad, sostenían que el déficit era responsabilidad de la proliferación de modelos, cobijada por la falta de normativas claras. CIFARA señalaba que las terminales tenían programas independientes y con ritmos dispares, e integraban la fabricación de piezas que se podrían demandar a la industria auxiliar, imposibilitando una mayor racionalización en los proveedores. ${ }^{35}$

Estas tensiones se acrecentaron durante la segunda mitad de la década de 1960, cuando la reducción de la demanda y la ampliación de las plantas generaron serios problemas con los costos internos. Las terminales presionaban para liberar la importación de partes. Las autopartistas respondían exigiendo el cumplimien-

\footnotetext{
34. BRONER, Julio y LARRIQUETA, Daniel, $\mathrm{La}$ revolución industrial..., Op. Cit.

35. Ídem, p. 186.
} 
to de los regímenes de promoción:

el primitivo decreto de promoción y... los que aseguraron la prórroga de las franquicias a favor de las empresas terminales, establecieron que vencido el término de su vigencia 'ningún retroceso debía producirse en los niveles de integración local alcanzados'. La racionalidad de este concepto es obvia: un régimen de promoción implica un sacrificio que el país realiza para alcanzar un determinado objetivo; sacrificio que en este caso se vio aumentado por lo que significó el equipamiento de la industria de partes en una actualización tecnológica sin precedentes para cumplir con la integración horizontal que, sin alcanzar empero el nivel económico óptimo para las condiciones del país, permitió que la producción automotriz no se alejara de un criterio aceptable de economicidad.... No es posible... que a partir de una fecha determinada se ignoren todas las motivaciones y su costo, y se pueda aceptar lisa y llanamente criterios que signifiquen la seguridad de retrocesos, no por falta de capacidad tecnológica..., ni por negligencia, ni mucho menos por falta de ética industrial de los fabricantes de partes, sino porque así pudiera convenir a los intereses de un sector particularizado. ${ }^{36}$

Las terminales aducían que el régimen generaba la "dependencia del proveedor único en algunos casos". CAIA respondía que justamente las terminales eran las que exigían que las piezas se entregaran bajo licencias, que salvo excepciones eran otorgadas por autopartistas internacionales a una sola firma en Argentina. Otro problema surgió en 1967, cuando el decreto 1.410 rebajó en general los aranceles de protección, significativamente en partes como baterías y piezas eléctricas. Esto llevó a

36. Argentina Automotriz, Buenos Aires, julio-agosto de 1967. las autopartistas a redoblar los reclamos contra la importación y por la ausencia de promoción específica a diferencia de las terminales. CIFARA en 1964 sostenía que:

Se instituyó un régimen de excesiva liberalidad para con las armadoras, consecuente con toda la política seguida en materia de radicación de capitales extranjeros, y se dejó muchas veces relegado el legítimo interés de los productores nacionales de partes. Se autorizaron planes que pocas veces se habrían de poder cumplir... y se instaló un número exagerado de plantas que producen una enorme cantidad de modelos, dificultando la racionalización de la producción de partes. Lo más grave y destacable... es que todas las deformaciones que aquí indicamos, fueron señaladas y remarcadas... por los sectores industriales afectados por esa situación, y por los especialistas que analizaron el problema. ${ }^{37}$

Las autopartistas achacaban los problemas a la "liberalidad" con que se trató a las terminales y a las intenciones de éstos por proveerse en el exterior, lo que afectaría el negocio de los autopartistas del país. Durante el resto de la década, estas tensiones no desaparecieron. Más aun, se agudizaron en los momentos previos a la renovación del régimen automotriz a comienzos de los '70. Veamos cómo se procesó este conflicto.

\section{1: la renovación del régimen automotriz}

En enero de 1970, se hizo público el proyecto de un nuevo régimen automotriz en reem-

37. Crisis, ¿̨adónde vamos?, Departamento de Investigaciones, CIFARA, 1964, pp. 80-81. 
plazo del que regía, con modificaciones, desde 1959. Con él se incrementaría la integración nacional de los vehículos que, en 1968, se ubicaba en $96 \%$ para autos y $88 \%$ para camiones; abonando la importación de partes permitidas un recargo de $40 \%$ y $20 \%$ respectivamente. En líneas generales, el proyecto de 1970 buscaba evitar la instalación de nuevas terminales y la proliferación de modelos, eliminar la prohibición de importar vehículos terminados y reducir aranceles, mantener el recargo aduanero en autopartes, como lo más relevante. En la encuesta que realizó la Secretaria de Industria a los sectores afectados, ADEFA no se pronunció como entidad puesto que no hubo acuerdo interno, ya que cada terminal actuaba en segmentos distintos: Fiat, IKA-Renault y Peugeot apoyaron la iniciativa; mientras que GM, Ford y Chrysler, que buscaban lanzarse al mercado de medianos, quisieron demorar1a. ${ }^{38}$ Por su parte, los autopartistas acordaron en aspectos claves como evitar proliferación de modelos, promover la descentralización geográfica, no retroceder en porcentajes de integración, o reducir precios de la industria por medios distintos a la desgravación de derechos de importación.

En relación al vínculo entre ambos, terminales y autopartistas pretendían imponer sus intereses. Las terminales buscaban limitar la obligación de integración nacional mientras que las autopartistas buscaban reforzarla. El debate se dio en torno a los costos de los automóviles, con sendos informes de los interesados: ADEFA en 1969; y CIFARA en 1970. Ambos reconocían un problema de costos que atribuían a diversos factores. Coincidían en los altos costos del abastecimiento local de materias primas y denunciaban ineficiencia del sector

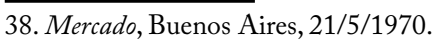

siderúrgico. Pero luego, cada una planteó su visión respecto a la baja productividad.

Las terminales explicaban que su baja producción redundaba en menor productividad. Se calculaba que el volumen mínimo para poner en funcionamiento una línea automotriz con tecnología de punta, solo con producción de motores, era de 250.000 unidades anuales. En Argentina el total no alcanzaba siquiera esta cifra. Para 1969 la fabricación fue de 218.590 unidades. Es decir, en la industria terminal no era económicamente viable la utilización de la última tecnología existente: mayores volúmenes de producción implicarían utilización de máquinas herramientas de tipo específico que, a diferencia de las universales, permitirían acelerar el ritmo de trabajo. Pero su empleo solo era rentable a grandes volúmenes porque, en aquel entonces, las específicas solo podían utilizarse para un modelo y debían ser amortizadas en el tiempo de vida de éste. La utilización de máquinas universales implicaba elevados tiempos muertos para la preparación de las herramientas para los diferentes lotes de producción.

Además, por la ineficiencia del autopartismo, debieron realizar inversiones extras para fabricar piezas, en especial en estampado, forjado y mecanizado. Parte de esta ineficiencia la atribuían a la falta de equipamiento adecuado y demandaban al Estado que se encargara de promover una modernización tecnológica:

Salvo excepciones, los establecimientos fabricantes de partes no cuentan con todos los equipos específicos de las tecnologías que abastecen. Lo corriente es encontrar maquinaria convencional que aunque sea relativamente nueva en cuanto a años de uso, presenta diseños que en general corresponden a proyectos antiguos... el em- 
pleo de técnicas avanzadas,... demandaría inversiones que sólo podrían ser absorbidas para niveles de producción de las terminales muy superiores. ${ }^{39}$

El desarrollo autopartista interesaba a las terminales porque les permitía deshacerse de una capacidad instalada desaprovechada. Por caso, esta es una de las razones que determinó la quiebra de IKA y su venta a Renault; que debió deshacerse de gran parte de las plantas que su antecesora había instalado para producir piezas.

Las excesivas inversiones... que obedecen a las razones antes citadas [la deficiencia de la industria autopartista], configuran el panorama actual de una industria terminal que presenta un equipamiento excesivo frente a las necesidades del mercado, lo que redunda en una capacidad ociosa... Esa capacidad ociosa se manifiesta a través de la comparación entre la capacidad máxima de producción posible de las empresas asociadas a ADEFA, que es de aproximadamente 242.000 unidades y de la producción efectivamente realizada en el año 1967 de 149.000 unidades, o sea un $38,39 \%$ de capacidad productiva no saturada. ${ }^{40}$

ADEFA señalaba que había capacidad ociosa en el autopartismo. Por eso, junto a la modernización del sector recomendaba una centralización. Los argumentos apuntaban a atacar la integración nacional, la imposición legal de un porcentaje mínimo de composición local para los autos fabricados en el país, a la que atribuían parte de la ineficiencia.

Los requerimientos de los elevados por-

39. ADEFA, Los factores que distorsionan la formación de los costos en la industria automotriz, T. I, 3, 1969, p. 34.

40. Ídem, T. I. 4, p. 3.

16 centajes de nacionalización de los países en vías de desarrollo han colocado a las empresas internacionales ante algunas alternativas de difícil resolución. Uno de ellos es que... para no perder mercados se han visto en la necesidad de instalar en todo el mundo fábricas dimensionadas para pequeños volúmenes... mientras que por el otro, la tecnología y las condiciones para competir internacionalmente las impulsan a una concertación de esfuerzos... los países en vías de desarrollo han insistido en la creación de una industria nacional del automotor que, debido a los pequeños volúmenes de producción, presenta características de trabajo intensivo. ${ }^{41}$

Decían no oponerse a la integración con piezas nacionales, sino al elevado porcentaje impuesto (90\%). Para ellos, no debía superar el $40 \%$.

Este 40\% de nacionalización es el límite máximo económico para los tramos inferiores dentro... de los países en vías de desarrollo. Está compuesto por el montaje y por la fabricación de partes que se obtienen mediante procesos tecnológicamente sencillos o bien que poseen en el mercado de reposición una importante demanda creciente, lo que les permite alcanzar mayores volúmenes de producción. Por encima del $40 \%$ y hasta un $80 \%$ ya se entra en la fabricación de los equipos eléctricos... y de los componentes y partes... del motor, caja de cambios y diferencial, con las economías de escala que es fácil suponer... Este valor del 75/80\% aparecería como el límite máximo teórico de nacionalización que, a falta de otras razones... tendría que alcanzar la industria automotriz en los países en vías de desarrollo. Superando el $80 \%$ se requieren fuertes inversiones en la matricería..., tropezándose además con los inconvenientes

41. Ídem, pp. 38-39. 
propios del proceso de estampado en pequeña serie... ${ }^{42}$

Los autopartistas deslindaban su responsabilidad en la elevación de los precios de vehículos, ya que éstos subieron por encima de los de las piezas. Argumentaban que la responsabilidad era de las terminales debido a la disminución de su productividad. En cuanto a la capacidad ociosa, proponían la ampliación del mercado y la diversificación, debido a que el problema se percibía en sectores que se dedicaban predominantemente a automotriz como estampado o partes eléctricas. Aunque reconocían que la sub-utilización de la capacidad era moneda corriente. En cuanto al cupo de integración, lo defendían como un problema de interés nacional.

No hay duda que a una empresa mundial que se instala en América Latina para construir máquinas, le conviene repartir el trabajo en distintas naciones-talleres, del mismo modo que lo hace en su país de origen con sus diversos proveedores... A esta empresa supranacional, que generalmente tiene filiales en varias naciones, puede resultarle económico encargar la chapa o el lingote a las acerías del país A, los cables al país $\mathrm{B}$ y los motores al país C. Esa empresa es la que produce la máquina y la coloca en el mercado único... es evidente el perjuicio para las economías nacionales que se prestan a desempeñar ese papel. El país A no pasará nunca de la etapa de la chapa y del lingote, el país B quedará haciendo cables y el país C, motores. ${ }^{43}$

En cuanto a su eficiencia, aseguraban tener un nivel que les permitiría competir en mercados

42. Ídem, p. 41.

43. CIFARA, Estudio técnico-económico de la industria nacional del transporte, Buenos Aires, 1970, p. 27. extranjeros, en especial a nivel regional.

Además, reclamaban fomento a la exportación. Por ejemplo, la implementación del draw-back para compensar el sobreprecio de la materia prima y una política de reintegros de cargas sociales y previsionales que "colocan a la industria argentina en condiciones desfavorables ante las legislaciones sociales menos avanzadas de los demás países de la zona”. ${ }^{44}$ Esto era reconocido por las terminales y parecía afectar al conjunto de la industria argentina. ${ }^{45}$

Finalmente, la legislación aprobada pareció responder más a los intereses autopartistas. En 1971, el Régimen de Reconversión sancionado prohibió la importación de vehículos hasta 1980, lo cual otorgó protección a las terminales. Se aplicó el sistema de "listas positivas", mecanismo propuesto por los autopartistas donde el recargo para la importación de partes se estableció según la disponibilidad de cada pieza en el mercado. Se fijaron porcentajes de importación de autopartes de $4 \%$ para automóviles, $7 \%$ para utilitarios y $10 \%$ para chasis de camiones y colectivos. También se incorporaban reintegros del $50 \%$ para exportaciones. Si bien había beneficios para ambos, los autopartistas salieron ganando debido a que el porcentaje de integración nacional solo se redujo levemente.

\section{Unidad frente a la clase obrera}

Si en algo coincidían ambos sectores, era en la necesidad de atacar las condiciones de la clase obrera, cuyas conquistas en el terreno laboral determinaban mayores costos. Una de las pre-

44. Ídem, p. 43.

45. Cronista Comercial, Buenos Aires, 19/08/68. 
ocupaciones eran las cargas patronales que debían pagar para costear los beneficios sociales. Según argumentaban las cámaras, los costos laborales eran elevados debido a ese ítem, en comparación a otros países de la región. En el análisis y propuestas de CIFARA, encontramos la queja sobre las cargas sociales y un pedido de reintegro (ver cita 44). ADEFA sugería que las cargas no constituían la principal causa del alza de costos, aunque señalaba que eran más elevadas que en otros países. En su informe comparaban las cargas sociales a nivel internacional: en Argentina, al igual que en Francia, los aportes laborales eran realizados por empresarios y trabajadores, a excepción de los casos de maternidad. Esto era una diferencia con Brasil, México, Italia o Alemania en donde el Estado contribuía a financiar el sistema de asignaciones y de seguridad social. En cuanto al aguinaldo, mientras aquí era de carácter obligatorio, en Brasil, México, Francia, EE.UU. o Italia no existía la imposición de abonarlo. En cuanto al porcentaje de aporte sobre el sueldo, en Argentina los trabajadores aportaban el 5\% mientras la patronal 25\%. En Brasil se calculaba que los trabajadores aportaban el $8 \%$ y la patronal $15 \% .{ }^{46}$

La comparación con Brasil era fundamental debido a que era el principal competidor. Las diferencias resultaban notorias en las condiciones de trabajo de uno y otro lado de la frontera. Como relata Juan Morrone, ex gerente de Producto de Chrysler, en Brasil los obreros aceptaban condiciones que los argentinos no hubieran tolerado:

Cuando uno veía las condiciones laborales de Brasil frente al mismo producto, decía: 'Si traemos estas condiciones laborales a la

46. ADEFA, Los factores que distorsionan, Op. Cit., T. II., 4.
Argentina, nos matan.'... Yo vi en Brasil mujeres que levantaban cajas de aluminio, bloques grandes, que los metían en la máquina con una mugre hasta por acá. Pintaban al costado de la línea de producción. Cosas que acá eran absolutamente impensables. Además, ellos tenían una oferta laboral enorme que no tenían problema. Allá si mañana hacían huelga, pasado no tenían trabajo porque tomaban a otro y listo. Y acá no era así. Es una cuestión demográfica. ${ }^{47}$

El ataque a las condiciones de los trabajadores argentinos resultaba una preocupación del conjunto de la burguesía del sector que los aunaba en el mismo reclamo: eliminar los elementos que encarecían el precio de la fuerza de trabajo.

Sancionado el régimen de 1971, la atención de las terminales se dirigió a otros ítems que afectaban su rentabilidad. Uno de los más relevantes fue el control de precios, mecanismo utilizado para contener la inflación que los empresarios cuestionaron, exigiendo para ello la reducción de los salarios. En medio de diferentes planes de contención del alza de precios, los de los vehículos evolucionaron por debajo de la inflación. En 1975, la economía, y el sector en particular, atravesaron otra crisis. ADEFA denunciaba desabastecimiento, multiplicación de unidades sin terminar, iliquidez, imposibilidad de compatibilizar programas de producción/ ventas/abastecimiento, mercado negro de materias primas, perjudicando a autopartistas y terminales, llevando al excesivo endeudamiento y descapitalización. Las autopartistas experimentaban una situación similar, quejándose de los altos costos, la demora en los cobros y

47. Entrevista a Juan Morrone, ingeniero industrial, ex Gerente de Producto de Chrysler Argentina, 13 de febrero de 2011. 
el crédito gravoso. Eso motivó quejas de las fábricas, advirtiendo que la falta de incentivo estaba fomentando la especulación. ${ }^{48}$ En junio, María Estela Martínez anunció un Acta de Compromiso con la industria automotriz para financiar la importación de insumos, y aseguró que "las empresas extranjeras... que actúen en la Argentina, tendrán toda la protección que le acuerdan nuestras leyes, para garantizar su completa expansión y crecimiento", mientras que el ministro Rodrigo reconocía el retraso de precios y prometía aliento a las exportaciones. ${ }^{49}$ No obstante, la situación no mejoró, en el contexto de un fuerte desabastecimiento de materias primas auxiliares (caucho, textil, plásticos, metales, etc.). A los reclamos, las terminales agregaban hechos de orden "político-laboral, que incidieron notablemente en los costos de producción”. ${ }^{50}$ A medida que la crisis avanzaba, la conflictividad laboral iba en aumento, lo que llevaba a las automotrices a exigir el disciplinamiento de los trabajadores.

La burguesía intentó la salida mediante el golpe de 1976, apoyado por prácticamente todas sus capas y fracciones. El derrumbe del precio internacional de las materias primas hacia fines de 1974 exacerbó los enfrentamientos. Los intentos de ajuste (el "Rodrigazo"), fueron abortados por la resistencia obrera, lo que terminó de alinear a la clase dominante en torno a la salida golpista. El ajuste demandaba, como paso previo, el disciplinamiento de la clase obrera, y ello no podía hacerse en democracia. En la Asamblea Permanente de Entidades Gremiales Empresarias (APE$\mathrm{GE}$ ), que encabezó la conspiración golpista, confluyeron la burguesía agropecuaria, el gran

48. Mercado, Buenos Aires, 24/4/1975.

49. Mercado, Buenos Aires, 26/6/1975.

50. Mercado, Buenos Aires, 28/8/1975. capital industrial y las capas más débiles de la industria. Sin embargo, esa amplia alianza no se mantuvo una vez que las Fuerzas Armadas se alzaron con el poder. Los puestos clave en la administración quedaron en manos de los representantes del programa "liberal desarrollista”, que procedieron a relanzar la acumulación mediante un aumento de la intensidad laboral y la reasignación de los acotados recursos hacia el capital más concentrado, revisando el sistema de protección. Se impuso una nueva correlación de fuerzas no solo en la relación capital-trabajo, sino también dentro de las filas de la clase dominante. En el caso estudiado, esto quedó plasmado con la renovación del régimen automotriz a fines de los '70. Entre los puntos principales se destacaba la rebaja arancelaria, el fin de la prohibición de importar y la igualación en el tratamiento de inversiones nacionales y extranjeras. Se sancionaron dos ítems que impusieron los intereses de las terminales por sobre los autopartistas: el levantamiento de la prohibición de integración vertical, posibilitando la fabricación de piezas por las terminales; y el abandono de restricciones sobre nuevos modelos. ${ }^{51}$ ADEFA acordó con el proyecto, y solo objetó los tiempos de implementación solicitando que fuera más gradual en la disminución de aranceles para vehículos completos. Las autopartistas señalaron que el nuevo régimen provocaría la bancarrota de varios. Argumentaban que la eficiencia no podría ser elevada facilitando las importaciones, sin atender cuestiones estructurales (alto precio de la materia prima, suministro eléctrico y comunicaciones; cargas sociales, falta de economías de escala, etc.). Agregaban que el incremento de los modelos generaría una mayor distorsión y disminuiría la demanda de insumos básicos. No obstante, se aprobó con la mayor parte de

51. Mercado, Buenos Aires, 29/6/1978. 
estos cambios. El golpe evidentemente modificó la relación de fuerzas al interior de la rama, con la imposición de la estrategia liberal-desarrollista que había tomado las riendas del Estado.

\section{Reflexiones finales}

El caso automotriz permite reflexionar sobre algunos de los problemas que plantea la interpretación dominante acerca de los enfrentamientos interburgueses durante la crisis orgánica de 1955-1976, que postula una falsa dicotomía entre fracciones de la burguesía que defienden el mercado interno y los "intereses nacionales", y otras (los "monopolios", el "capital imperialista"), que adscribirían al "ajuste liberal”. Como mostramos, la burguesía industrial en Argentina, grande o chica, tiene una debilidad que le impide adscribir al denominado programa "liberal". Prácticamente no existe industria que pueda subsistir sin protección frente a la competencia extranjera. Es sabido que los pequeños capitales nacionales, entre los que estaban la mayoría de los autopartistas, partiendo de esta debilidad se erigieron en impulsores de políticas proteccionistas, bajo el programa de "liberación nacional". Sin embargo, erróneamente, se suele presentar a los grandes capitales como defensores de un ajuste que busca reducir al mínimo la intervención estatal y eliminar las barreras proteccionistas. A lo largo de este trabajo mostramos que no es el caso de las multinacionales automotrices. Estos tenían una política dual respecto a la protección: mientras exigían mayor eficiencia a sus proveedores, y solicitaban al Estado importar insumos dejando desprotegidos a los autopartistas nacionales, exigían la máxima protección para los autos que fabricaban. Esta propuesta coincidió con la del resto de los grandes industriales, que se organizaron en el CEA y esgrimieron el programa que hemos denominado liberal-desarrollista. Estos capitales coincidían parcialmente con las propuestas liberales de la burguesía agropecuaria, pero no podían asumir como propio su programa. La burguesía agropecuaria y los industriales de mayor tamaño coincidían en que, para superar la crisis de acumulación del capitalismo argentino, era necesario emprender un ajuste de las variables económicas. Los gastos del Estado, los salarios y los recursos para subvencionar al capital industrial debían recortarse. Sin embargo, diferían en el alcance que atribuían al ajuste. Para la burguesía agropecuaria, que financiaba las políticas proteccionistas resignando porciones crecientes de renta, el ajuste debía alcanzar a todos los industriales ineficientes. Debía retirarse la tutela estatal y dejar librado a su suerte a todo capital que no tuviera la eficiencia o los costos que le permitieran competir de igual a igual en el mercado mundial. Pero esa propuesta no podía ser asumida por el capital industrial de mayor tamaño, que no estaba en condiciones de prescindir de la protección. En este punto, la propuesta de la gran burguesía industrial se distanciaba de los postulados clásicos del liberalismo: necesitaban un Estado que intervenga reasignando recursos en su favor y restringiendo la libre competencia para su supervivencia. Es por ello que el ajuste propuesto por los miembros del CEA (entre ellos, las terminales automotrices) se limitaba a reducir la protección a un nivel en el que, mientras los capitales más débiles fueran a la quiebra, los más grandes pudieran subsistir.

Recibido: 01-11-2016

Aceptado: 26-05-2017

Publicado: 07-06-2018 


\section{Bibliografía}

AA.VV., "Coincidencias programáticas del plenario de organizaciones sociales y partidos políticos", en MINISTERIO DE ECONOMÍA, Politica económica para la reconstrucción y la liberación nacional, Legislación Económica, Buenos Aires, 1975, pp. 213 -222.

AZPIAZU, Daniel, La industria celulósica-papelera, su evolución histórica y perspectivas futuras, INPE, Buenos Aires, 1977.

BAUDINO, Verónica, La estrategia de la Unión Industrial Argentina 1966-1976, Tesis Doctoral, Universidad de Buenos Aires, 2012.

BAUDINO, Verónica, “La Fundación Mediterránea y la burguesía nacional”, en Razón y Revolución, Buenos Aires, 2004, No 12, pp. pp. 161-171.

BARANSON, Jack, La industria automotriz en los países en desarrollo, Tecnos, Madrid, 1971.

BASUALDO, Eduardo, Sistema politico y modelo de acumulación en la Argentina, Universidad Nacional de Quilmes, Bernal, 2001.

BRENNAN, James y ROUGIER, Marcelo, Perón y la burguesía nacional, Lenguaje Claro, Buenos Aires, 2013.

BRONER, Julio y LARRIQUETA, Daniel, La revolución industrial argentina, Sudamericana, Buenos Aires, 1969.

CASTELLANI, Ana, Estado, empresas y empresarios. La construcción de ámbitos privilegiados de acumulación entre 1966 y 1989, Prometeo, Buenos Aires, 2009.

CASTRO, Claudio, "De proveedor del Estado a empresa multinacional: Siderca entre 1960 y 1996 ”, en ROUGIER, Marcelo (compilador) Estudios sobre la industria argentina, Lenguaje Claro, Buenos Aires, 2013.

Estudio de caso relativo a la fabricación de embragues y discos de embrague en Argentina y Chile, CEPAL, Santiago, 1970.

FITZSIMONS, Alejandro, "Notas sobre la valorización de los capitales extranjeros automotrices en Argentina (1959-63)", ponencia presentada en VII Jornadas de Economía Crítica, Sociedad de Economía Crítica, La Plata, 2014.

GORENSTEIN, Silvia, "El Complejo Petroquímico Bahía Blanca: algunas reflexiones sobre sus implicaciones espaciales”, en Desarrollo Económico, Buenos Aires, 1993, V.32, No 128, pp. 575-601.

GRAMSCI, Antonio, Notas sobre Maquiavelo, sobre la politica y sobre el Estado moderno, Nueva Visión, Buenos Aires, 2003.

HEREDIA, Mariana, "El proceso como bisagra. Emergencia y consolidación del liberalismo tecnocrático: 
FIEL, FM y CEMA", en PUCCIARELLI, Alfredo (coordinador) Empresarios, tecnócratas y militares, Siglo XXI, Buenos Aires, 2004.

MUCHNIK, Daniel, Argentina modelo, Manantial, Buenos Aires, 1998.

NOFAL, María, Absentee Entrepreneurship and the Dynamics of the Motor Vehicle Industry in Argentina, Praeger, New York, 1989.

PEÑA, Milcíades, Industrialización y clases sociales en la Argentina, Hyspamérica, Buenos Aires, 1986.

RAMÍREZ, Hernán, "La fundación Mediterránea y de cómo construir poder. La irrupción del interior en el diseño de la política económica argentina”, en História Econômica E̊ História de Empresas, No 2, V. 4, 2001,pp. 131-161.

SÁBATO, Jorge, La clase dominante en la Argentina moderna, Imago Mundi, Buenos Aires, 1991.

SANZ CERBINO, Gonzalo, "La lógica del enemigo. Los programas de la burguesía argentina y sus límites, 1955-1976”, en Razón y Revolución, Buenos Aires, 2016, No 29, pp. 151-198.

SARTELLI, Eduardo (compilador) La crisis orgánica de la sociedad argentina, Editorial de la Facultad de Filosofía y Letras, Buenos Aires, 2011.

SARTELLI, Eduardo, La sal de la tierra. Clase obrera y lucha de clases en el agro pampeano (1870-1952), Ediciones ryr, Buenos Aires, 2017, en prensa.

SCHVARZER, Jorge, Empresarios del pasado. La Unión Industrial Argentina, CISEA-Imago Mundi, Buenos Aires, 1991.

SIDICARO, Ricardo, Los tres peronismos. Estado y poder económico 1946-55/1973-76/1989-99, Siglo XXI, Buenos Aires, 2002.

SIMONASSI, Silvia, "Entre la adhesión activa y el desencanto. Acerca de los industriales metalúrgicos del Gran Rosario y el Proceso”, en Avances del CESOR, Rosario, 1998, No 1, pp. 95-107.

SIMONASSI, Silvia, Historias del Metal. Industria e industriales metalúrgicos en Rosario, 1973-1983, Tesis de Maestría, Facultad Latinoamericana de Ciencias Sociales (FLACSO), 2004.

SOURROUILLE, Juan, Transnacionales en América Latina. El complejo automotor en Argentina, Nueva Imagen, México, 1980.

VERBITSKY, Horacio, BOHOSLAVSKY, Juan Pablo, Cuentas pendientes. Los cómplices económicos de la dictadura, Siglo XXI, Buenos Aires, 2014.

VICENTIN, Enzo, "La empresa automotriz IASFSA en Santa Fe. Características de una experiencia en los márgenes (1959-1969)”, en Avances del CESOR, Rosario, 2013, № 10, pp. 9-33. 